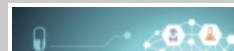 \\ Chemical Education

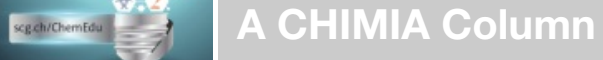 \\ Topics for Teaching: A Didactic Tool \\ The Molecule of the Week: A Didactic Tool for Teaching General Chemistry
}

\section{Antonio Togni*}

${ }^{*}$ Correspondence: Prof. Dr. A. Togni; E-mail: atogni@ethz.ch; Department of Chemistry and Applied Biosciences, ETH Zürich, HCI H 239, Vladimir-PrelogWeg 2, CH-8093 Zurich

Abstract: The molecule of the week is regularly used by the author in his first-semester course General Chemistry I (Inorganic Chemistry) to illustrate, exemplify, and deepen fundamental aspects and concepts treated in the course. Pure sulfuric acid and its autoprotolysis is used to introduce the concepts of protochemical window and superacidity. The drug Auranofin serves at showing fundamental aspects of gold redox and coordination chemistry and the widely used disinfectant trichloroisocyanuric acid (TCICA) exemplifies redox processes with organic compounds.

\section{Keywords: Acid-base equilibria - Coordination compounds ·} General chemistry $\cdot$ Redox reactions

For chemistry, chemical engineering and interdisciplinary sciences curricula at ETH, General Chemistry courses in the first study year are subdivided from day one on into Inorganic, Organic, and Physical Chemistry and taught by three different professors representing the corresponding Institutes. While this is not necessarily common at many other universities worldwide, it offers the opportunity to show the characteristics of the classical subdisciplines of chemistry and possibly to confer some degree of specialization already at a very early stage. Within this frame, I have been teaching for several years the first-semester class Allgemeine Chemie I (Anorganische Chemie). The core topics are acids and bases, redox reactions, and coordination chemistry with a clear emphasis on equilibria mainly in aqueous systems. While it is imperative that the relatively simple underlying concepts need to be learned and understood by the students in view of more advanced courses, it is also true that teaching such fundamental aspects may be affected by several difficulties. How does an instructor generate and sustain the interest of the students? How can one convey the importance of the basics and their relevance for the understanding of more complex aspects of chemistry? In more simplistic terms, the question to ask is: How do I turn the potentially tedious and very dry content of my lectures into an appealing and interesting learning experience for the students? In order to answer this question, one needs to realize and make understandable that a connection between the even most simple and basic concepts and real-life chemical phenomena and compounds can be established in both directions.

Drawing from these considerations and taking inspiration from The Molecule of the Week collection of the American Chemical Society, ${ }^{[1]}$ I present every week a new molecule (Molekül der Woche, $\mathrm{MdW}$ ) and connect it to the contents just discussed or to be explained later. Thus, the criteria for choosing a specific molecule are closely related to the subject matter being conveyed by the lecture. However, every MdW is also intended to illustrate further aspects going well beyond simple concepts and, thus, it is not just a mere example. This very idea should become clear by looking at the examples of MdW's that I have been using in the course of the past several years. Students always very much appreciate every week's MdW and look forward to this enriching and often surprising intermezzo in the otherwise somewhat monotonous descriptions and explanations of the intended contents.

Sulfuric acid is a strong biprotic acid that is almost fully dissociated in diluted aqueous solution. It would therefore qualify as a rather boring example of a Brønsted acid of the type $\mathrm{H}_{2} \mathrm{~A}$ in a more conventional teaching approach. However, $\mathrm{H}_{2} \mathrm{SO}_{4}$ displays a number of instructive features going well beyond its strength. $\mathrm{H}_{2} \mathrm{SO}_{4}$ is produced as a bulk chemical on a scale of more than 200 million tons per year worldwide. ${ }^{[2]}$ To visualize this enormous quantity, I show a picture of the Lago di Lei (Fig. 1), the fifth largest Swiss barrier lake, located in the Splügenpass region. This lake has a capacity of 197 million $\mathrm{m}^{3}$ (tons of water). Watching at this lake from a nearby hiking trail means grasping at a glance a mass of 200 million tons.

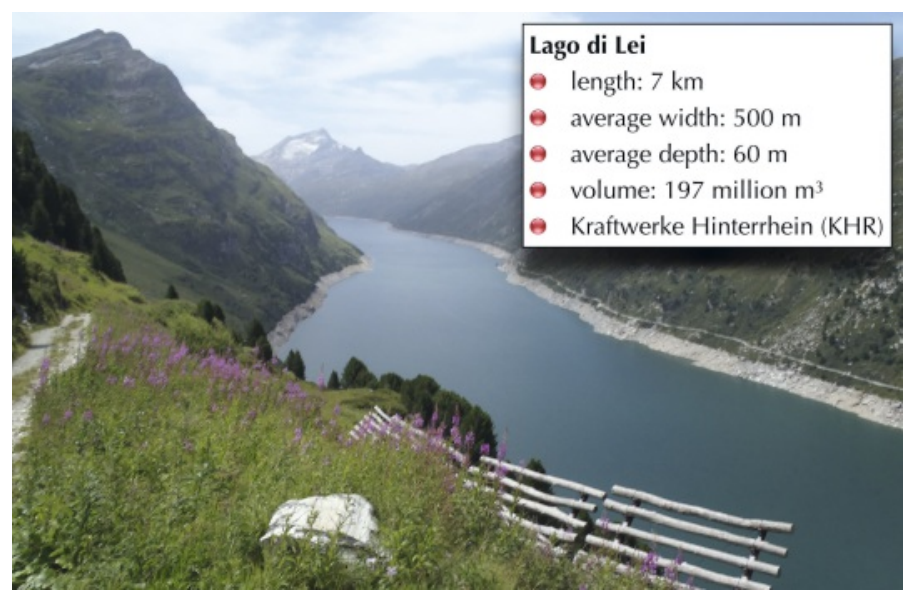

Fig. 1. Lago di Lei: visualizing a mass of ca. 200 million tons of water (photo by the author).

Pure sulfuric acid can be used as a protic solvent, very much in analogy to water. Thus, besides the classical dissociation constants in water, two important aspects become evident: the autoprotolysis constant $K_{\text {ap }}\left(\mathrm{p} K_{\mathrm{ap}}=3.6\right)$ and the existence and structural nature of the protonated form $\mathrm{H}_{3} \mathrm{SO}_{4}^{+}$, as well as its isolation as a $\mathrm{SbF}_{6}^{-}$salt $^{[3]}$ (Fig. 2).

The value of $\mathrm{p} K_{\mathrm{w}}=14$ for the autoprotolysis of water coincides with the common length of the $\mathrm{pH}$ scale in water (0 to 14 ). Hence, by analogy, the length of the $\mathrm{pH}$ scale in sulfuric acid is only 3.6 logarithmic units instead of 14. However, how are the two scales located with respect to each other on a possible scale of absolute Brønsted acidity? To answer this question, the 


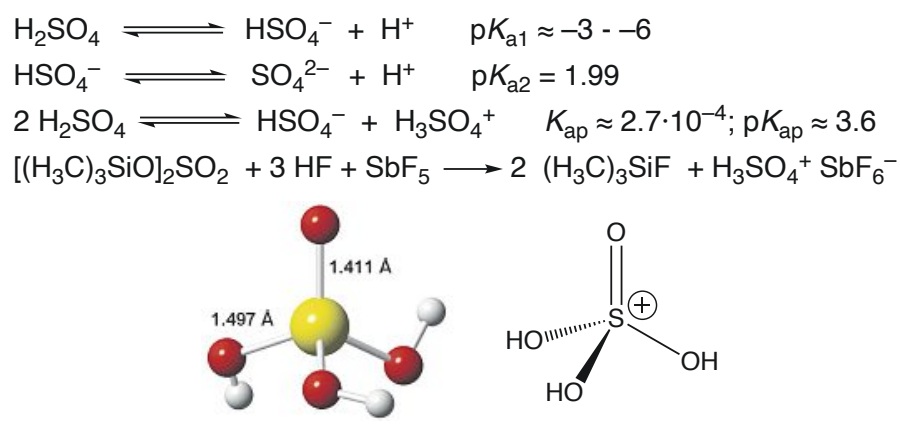

Fig. 2. The essential equilibrium constants for proton dissociations of sulfuric acid and the structure of its protonated form.

concept of the protochemical window ${ }^{[4]}$ based on the chemical potential of the proton in different media needs to be introduced, thereby establishing the link to a later course in Thermodynamics. Finally, pure sulfuric acid, with its Hammett acidity function $H_{0}$ $=-12$, represents (by definition) the boundary between conventional acidic media and superacids. ${ }^{[5]}$

A very special superacidic compound is auric acid, $\mathrm{HAuCl}_{4}$ that is formed upon oxidation of gold in aqua regia. The conjugated base of $\mathrm{HAuCl}_{4}$ is the square-planar tetrachloroaurate(III) anion, a simple $d^{8}$ complex. A discrete and no longer superacidic dihydrate form of $\mathrm{HAuCl}_{4}$ is the salt shown in Fig. 3, in which the counterion of $\left[\mathrm{AuCl}_{4}\right]^{-}$is the crownether-stabilized ion $\left[\mathrm{H}_{5} \mathrm{O}_{2}\right]^{+}$, the so-called Zundel ion.[6]
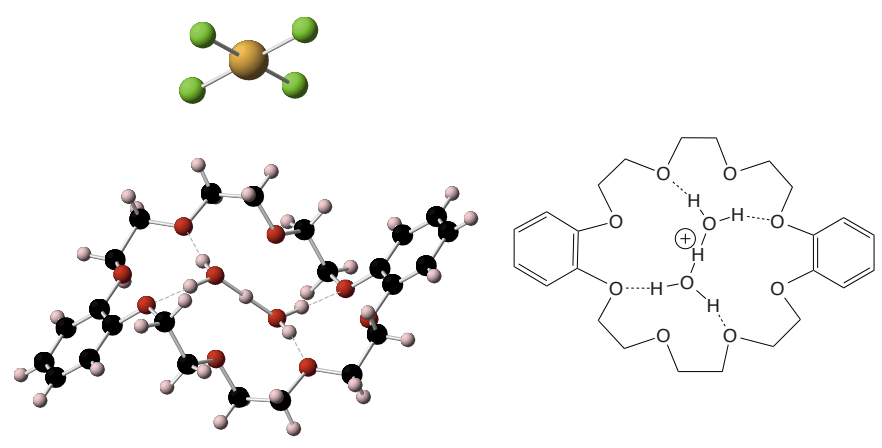

Fig. 3. The molecular structure of a crownether adduct of auric acid containing the stabilized $\left[\mathrm{H}_{5} \mathrm{O}_{2}\right]^{+}$ion.

$\mathrm{HAuCl}_{4}$, as a very hygroscopic hydrate, is one of the most common starting materials for the preparation of a variety of $\mathrm{Au}$ complexes. It is readily reduced in water/alcohol mixtures by organic sulfides - typically dimethylsulfide or tetrahydrothiophene that are thereby oxidized to the corresponding sulfoxides - to afford $\mathrm{Au}(\mathrm{I})$-chloro complexes containing a labile sulfide ligand. The latter can be easily replaced by other donors in a simple ligand substitution reaction. Similarly, the chloro ligand undergoes substitution reactions with anionic ligands such a thiolates (Scheme 1).

\footnotetext{
$2 \mathrm{Au}+2 \mathrm{NOCl}+3 \mathrm{Cl}_{2}+2 \mathrm{HNO}_{3}$
}

$2 \mathrm{HAuCl}_{4}+4 \mathrm{NO}_{2}$

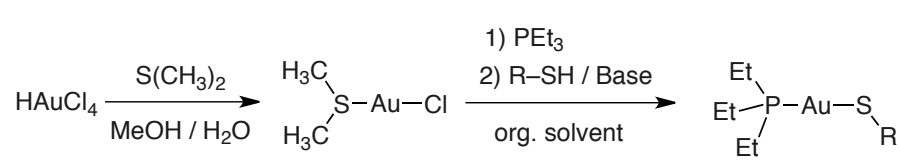

Scheme 1. Fundamental redox and ligand substitution reactions of gold.
This is the underlying fundamental redox and coordination chemistry of gold that is ideally represented by Auranofin (Fig. 4), a $\mathrm{Au}(\mathrm{I})$ complex containing a D-glucose-derived thiolato ligand and triethylphosphine and giving the typical linear coordination geometry for this $d^{10}$ center. Auranofin is a FDA-approved compound for the treatment of rheumatic arthritis, currently being repurposed in connection with completely different diseases.[7]

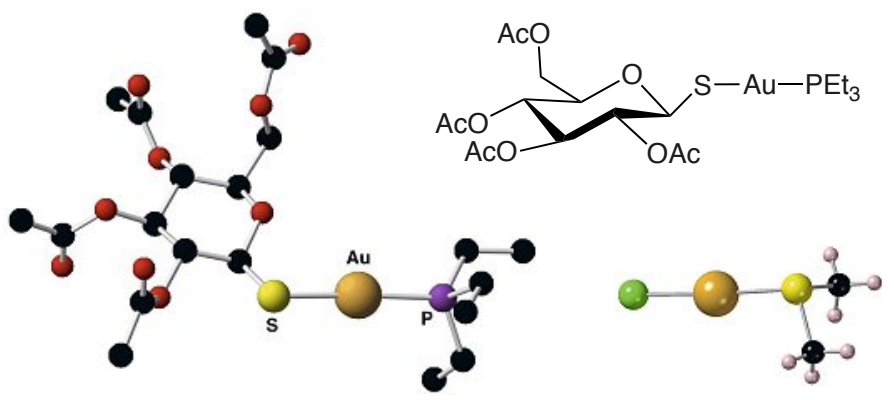

Fig. 4. The molecular structure of Auranofin and of the simple precursor $\left.\left[\mathrm{AuCl}\left(\mathrm{SMe}_{2}\right)\right]\right]^{[8]}$

Auranofin, a unique example of a gold-containing drug, thus represents a fruitful condensate of a variety of fundamental concepts treated in a general-chemistry course and helps interlinking acidbase, redox and coordination chemistry.

A third example in this brief overview of molecules of the week, a compound with the remarkable elemental composition $\mathrm{C}_{3} \mathrm{Cl}_{3} \mathrm{~N}_{3} \mathrm{O}_{3}$ shall also be mentioned: trichloroisocyanuric acid (TCICA, 1,3,5-trichloro-1,3,5-triazine-2,4,6(1H,3H,5H)trione). ${ }^{[9]}$ Its synthesis, starting with the reaction between chlorine and sodium cyanide is shown in Scheme 2. TCICA is produced on a scale of $10^{5}$ tons per year and is widely used as a disinfectant, e.g. in swimming pools, or as bleaching agent. It can also be used in a number of redox processes involving organic compounds, e.g. the conversion of secondary alcohols to ketones. ${ }^{[10]}$ Very recently, my research group has shown that TCICA can be used as the primary oxidant to generate polyfluorinated derivatives of organic compounds of phosphorus, sulfur, tellurium, and iodine mostly in their highest formal oxidation state. ${ }^{[11]}$

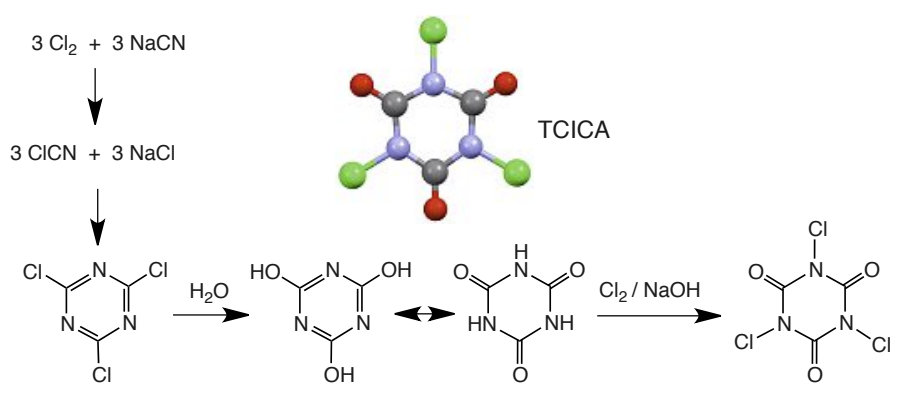

Scheme 2. Synthesis and structure of TCICA.

In conclusion, a carefully chosen molecule of the week may well serve the purpose of reviewing, consolidating, and interconnecting basic concepts of general chemistry. It also allows to link general chemistry to more current research aspects.

Received: June 7, 2020

[1] This popular feature has been known since almost 20 years, See: https:// www.acs.org/content/acs/en/molecule-of-the-week.html

[2] See: http://essentialchemicalindustry.org/chemicals/sulfuric-acid.html

[3] R. Minkwitz, R. Seelbinder, R. Schöbel, Angew. Chem. Int. Ed. 2002, 41, 111. 
[4] a) D. Himmel, S. K. Goll, I. Leito, I. Krossing, Angew. Chem. 2010, 122, 7037; b) D. Himmel, S. K. Goll, F. Scholz, V. Radtke, I. Leito, I. Krossing, ChemPhysChem 2015, 16, 1428 .

[5] For a general reference, see: G. A. Olah, G. K. S. Prakash, Á. Molnár, J. Sommer, 'Superacid Chemistry', 2nd ed., Wiley, New Jersey, 2009.

[6] a) M. Calleja, K. Johnson, W. J. Belcher, J. W. Steed, Inorg. Chem. 2001, 40, 4978; b) For a review, see: C. A. Reed, Acc. Chem. Res. 2013, 46, 2567.

[7] a) C. Roder, M. J. Thompson, Drugs $R D$ 2015, 15, 13. b) X. Zhang, K. Selvaraju, A. A. Saei, P. D’Arcy, R. A. Zubarev, E. S. J. Arnér, S. Linder, Biochimie, 2019, 162, 46.
[8] a) X-ray crystallographic structure of Auranofin: D. T. Hill, B. M. Sutton, Cryst. Struct. Commun. 1980, 9, 679; b) X-ray crystallographic structure of $\left[\mathrm{AuCl}\left(\mathrm{SMe}_{2}\right)\right]$ : P. G. Jones, J. Lautner, Acta Cryst. C: Cryst. Struct. Commun. 1988, 44, 2089.

[9] a) G. A. Hiegel, 'e-EROS, Encyclopedia of Reagents for Organic Synthesis', 2001, DOI: 10.1002/047084289X.rt209; b) U. Tilstam, H. Weinmann, Org. Proc. Res. Devel. 2002, 6, 384.

[10] M. A. Zolfigol, F. Shirini, A. G. Choghamarani, Synthesis 2006, 2043.

[11] See, e.g.: D. Bornemann, C. R. Pitts, C. J. Ziegler, E. Pietrasiak, N. Trapp, S. Küng, N. Santschi, A. Togni, Angew. Chem. 2019, 131, 12734. 